\title{
Side Effects of Insecticides on Beneficial Insects: A Practical Tool to Identify Organic Agroecosystems
}

\author{
JA Gómez Guzmán and R González Ruiz* \\ Department of Animal Biology, Vegetable Biology And Ecology, Jaen University, Spain
}

*Corresponding author: R González Ruiz, Department of Animal Biology, Vegetable Biology And Ecology, Jaen University, Spain.

Received Date: December 05, 2019

Published Date: December 09, 2019

\section{Abstract}

In order to achieving sustainability, integrated pest management (IPM) represents a remarkable improvement over previous conventional approaches, so optimizing the effectiveness of the entomophagy activity of natural enemies of pests is a determining factor. IPM does not necessarily require the suppression of insecticides, but rather affects the need to reduce their dependence, by eliminating unnecessary applications. However, the correct integration of chemical and biological control is essential part of sustainable pest management, for which a correct interpretation of the impact of insecticide treatments, is required. In IPM agroecosystems a great proportion of non-target insects are mainly affected by sublethal dose/ concentration values. A sublethal dose/concentration defined as inducing no apparent mortality in the experimental population. The effects induced have been described affecting biology, physiology, or behavior of individuals or populations that survive to the exposure to a toxicant at lethal or sublethal dose/concentration. The set of behavioral modifications provides insects with an escape mechanism from the toxic effects of pesticides, which has been called behavioral resistance, as the first barrier or detoxification mechanism.

For the correct integration of insecticide applications and biological control, the influence of the insecticide side effects on beneficial insects should be evaluated. Recent studies suggest that, as in both conventional olive / IPM orchards, these species frequently show behavioral resistance, while in organic crops, their populations lack it. There seems to be a close relationship between the application of insecticides and the development of behavioral resistant populations. This finding has suggested establishing a practical procedure based on the realization of smallscale field applications, to subsequently monitor beneficial insect reactions, useful for identifying ecological agroecosystems. The implications of the implementation of this new methodology are discussed.

Keywords: Sublethal effects; Insecticides; Behavioral resistance; Beneficial insects; Olive pests; Predators; Parasitoids; Conventional management; IPM; Organic management

\section{Introduction}

In order to achieving sustainability, integrated pest management (IPM) represents a remarkable improvement over previous conventional approaches [1]. This crop production and phytosanitary protection model combines different management strategies and practices for healthy crops, to bring the pest organism to acceptable limits with the least possible ecological disturbance [2]. This includes the establishment of population thresholds for pests, which determine the need for chemical control, minimizing risks to human health and beneficial organisms. Currently, an area of 392,362 hectares of olive groves corresponds to IPM in Andalusia (southern Spain), which according to the regional government, it represents $71 \%$ of the total area dedicated to olive cultivation.

IPM does not necessarily require the suppression of insecticides, but rather affects the need to reduce their dependence, by eliminating unnecessary applications. A well-developed IPM program, based on science, provides a wide range of techniques and offers new possibilities for pest control, which is obviously dependent on the use of pesticides [3]. In spite of this, insecticides represent essential elements on which the sustainability of an integrated management program depends, and it is very likely that this will continue as long as these products are available, effective and economically available [4]. With this objective, IPM programs resulted in safer and more judicious use of pesticides, flexible enough to integrate information about their impact on pests and their natural enemies, maintaining the quality of the ecosystem $[3,5]$.

Among the IPM objectives are to successfully prevent the emergence of resistant populations, protecting beneficial insects by enhancing their action [6], which has been focused on: i / The conservation / enhancement of natural populations of beneficial 
insects through to effective management of the agricultural environment (natural control), and ii /The increase of their populations through mass releases in the area of cultivation (biological control). Both allow to manage the pests efficiently and are compatible with the environment and with other control tactics $[7,8]$. First point includes habitat management, such as the establishment of an herbaceous plant cover, which, in addition to limiting the erodibility [9], is intended to enhance the natural control mechanisms [10-17].

Since insecticides constitute an essential part of IPM, this approach makes it necessary to evaluate their impact on beneficial fauna [4]. Most of the existing studies analyze the lethal effect of insecticides, including synthetic and natural products, but research on the sub lethal effects is still scattered. In field crops, lower doses / concentrations of insecticide occur, after the application is degraded by factors such as rainfall, temperature and sunlight. This means that a great proportion of non-target insects are mainly affected by sublethal dose/concentration values [18]. A sublethal dose/concentration defined as inducing no apparent mortality in the experimental population [19]. It is stated that, in general, doses / concentrations of insecticide below the lethal median (LD50 / LC50) are considered sublethal [20]. Sublethal effects have been described affecting biology, physiology, or behavior of individuals or populations that survive to the exposure to a toxicant at lethal or sublethal dose/concentration [4,20]. The sublethal effects may be manifested as reductions in life span, development rates, population growth, fertility, fecundity, changes in sex ratio, deformities, feeding, searching and oviposition [21-23]. The sublethal doses / concentrations of insecticides cause many alterations in the behavior of insects, interfering with their chemical communication system, thus reducing the chances of efficient localization of a pheromone source [20]. Among the induced symptoms have been described: jerky movements, overexcitation and hyperactivity [24-27]. Stimulation, as well as depression, of general locomotor behavior has also been cited, both for walking and for flying, causing uncoordinated or even convulsive movements, which therefore negatively affect reproductive processes, host location, dispersion, migration and food [4,21-23]. Nonetheless, these effects do not necessarily cause mortality of affected individuals, since the use of the term "insectistatics" [28] is suggested to apply it to those agents that can interfere with the processes of growth and reproduction, without necessarily killing. Quite the contrary, this set of behavioral modifications provide insects with an escape mechanism from the toxic effects of pesticides, which is why they have been called behavioral resistance since it provides the first barrier or mechanism of detoxification. The affected insects having this skill show hyperreflexia, with a trend to start the flight more easily [29-31].

Among the side effects of insecticides, it has been reported that beneficial arthropods are severely affected by sublethal effects $[4,19,20]$, although their impact has often been overlooked or underestimated. The determination of the side effects of insecticides acquires special relevance when considering the evolution of their populations in agricultural ecosystems. In the European Union, the registration and selection of insecticides for inclusion in IPM programs requires knowing their side effects on non-target organisms [32, 33]. As indicated in Table 1, dimethoate stand out in olive growing, being the most common insecticide, in both Conventional and IPM, among which the main difference consists in the criteria that determine the application of the insecticide. In the first case they are applied routinely, while in IPM their use is determined by the establishment of pest's population thresholds, which implies a considerable saving of insecticides with respect to conventional management. In view of the notable differences between them, the need to assess the impact of this reduction in the application of insecticides on the behavior of the populations of beneficial insects has been raised [34,35]. Since Insecticide applications induce behavioral modifications in natural enemies' insects affected by sublethal doses, it is likely their effects have an impact on the capture rates recorded in monitoring commonly used in olive growing, devices, such as the sticky chromatic traps, $[15,36]$. In order to detect anomalies in the capture rates of nontarget insects, field experiments based on experimental insecticide applications on a small scale have been carried out, as a trigger for behavioral reactions of insects affected by sub lethal doses. The hypothesis of these studies is based on the statement that the beneficial insects under the managements that commonly include the application of insecticide (conventional, IPM) have most likely developed behavioral patterns that are a first step in acquiring resistance [4]. Therefore, insect species affected by sublethal doses would have developed lineages with behavioral modifications that would allow them to adapt to relatively frequent contact with insecticides, unlike what would happen in ecologically managed agroecosystems.

Table 1: Characterization of the different types of olive management according to pesticide applications (Period 2007- 2017; Spanish Agricultural Committee of Organic Agriculture).

\begin{tabular}{|c|c|c|c|c|}
\hline \multirow{4}{*}{ Olive Pest } & \multirow{4}{*}{ Active Principles } & \multicolumn{3}{|c|}{ Management } \\
\hline & & Conventional & IPM & Organic \\
\hline & & Volume-Weight & Volume-Weight & Volume-Weight \\
\hline & & (avg/ Ha\&year) & (avg/ Ha\&year) & (avg/ Ha\&year) \\
\hline Aceria oleae & $\mathrm{S}(80 \%)$ & $1,4 \mathrm{~kg} / \mathrm{Ha}$ & $0,75 \mathrm{~kg} / \mathrm{Ha}$ & --- \\
\hline Prays oleae & Dimethoate $40 \%$ & $0,9 \mathrm{~L} / \mathrm{Ha}$ & $0,3 \mathrm{~L} / \mathrm{Ha}$ & --- \\
\hline Euzophera pinguis & Chlorpyrifos $48 \%$ & $1,5 \mathrm{~L} / \mathrm{Ha}$ & $0,75 \mathrm{~L} / \mathrm{Ha}$ & --- \\
\hline Phloeotribus scarabaeoides & Dimethoate $40 \%$ & 0,9 L / Ha & $0,45 \mathrm{~L} / \mathrm{Ha}$ & --- \\
\hline Bactrocera oleae & Dimethoate $40 \%$ & $1,8 \mathrm{~L} / \mathrm{Ha}$ & $0,9 \mathrm{~L} / \mathrm{Ha}$ & --- \\
\hline
\end{tabular}




\section{Discussion}

It is obvious to consider that the frequency of the insecticide application constitutes the main limiting factor of the diversity and abundance of the community of beneficial insects. It was also one of the main triggers for the implementation of Integrated Pest Management [1-3]. However, not all IPM models have allowed the desired sustainability to be achieved, nor have they achieved the desired effectiveness, frequently due to the lack of integration and coordination of the different program elements [37]. The integration of chemical and biological control can be part of sustainable pest management; therefore, it is essential to know the lethal and sublethal effects of insecticides on natural enemies to maximize the compatibility between these two tactics. This has led to the return of insecticides as a central element in pest control, which explains why recent studies do not allow to establish a clear differentiation between the IPM and Conventional management, while its deficiencies are especially evident when comparing any of these two managements with organic management [38]. Although compared to conventional management, IPM represents an average reduction in the use of insecticides of at least $50 \%$, it has been proven to be nonetheless insufficient to ensure the sustainability of the populations of beneficial insects and optimize their entomophagous effectiveness [35,38].

In addition to the lower diversity and abundance, the influence of the side effects of insecticides in the beneficial insects must be assessed for the correct interpretation of data from population monitoring. Recent studies suggest that, as in conventional agroecosystems, in IPM these species show very frequently behavioral resistance (BR+), while in organic crops, they lack it (BR-) [34,35]. A close relationship seems to exist between insecticide application and the development of behavioral resistant populations. This finding has suggested establishing a practical procedure based on the realization of small-scale field applications, to subsequently monitor the reactions of beneficial insects, useful to identify ecological agroecosystems, characterized by the absence of behaviorally resistant lineages. Among the species of beneficial insects potentially capable of developing behavioral resistance in agroecosystems subject to insecticide application, are species of the common green lacewings of the carnea-complex, such as Chrysoperla agilis, of special importance in spanish olive groves [35,39], the thysanopteran Aeolotrhips intermedius predator, [34] and the parasitoids Pnigalio mediterraneus, Ageniaspis fuscicollis and Chelonus eleaphilus [35]. These species have a higher capture rate in chromatic traps, which is attributed to symptoms caused by the sub lethal doses [24-27], such as spasmodic movements, overexcitement, hyperactivity, irritation / repellency reaction, thus avoiding contact with surfaces treated. These effects are common to a wide range of insecticides, including organochlorine [40,41], pyrethroids [31,41-43], organophosphates [41,44] and carbamates [41]. The set of behavioral effects are intended to avoid contact with the impregnated surfaces by the insecticide, thus chromatic traps represent shelter areas. These behavioral adaptations should lead to greater survival of the affected insects, as a first step in the selection of physiologically resistant lineages to insecticides. Regarding common green lacewings, resistance of Chrysoperla carnea has been indicated to pyrethroids, organophosphorous insecticides, carbamates [45] abamectin and organochlorine insecticides [37]. Therefore, for this type of insects, capable of developing behavioral resistance $(\mathrm{BR}+)$, we conclude that its higher frequency of capture in chromatic traps of treated areas can be considered as an indicator of the disturbance caused by insecticide applications.

Among the beneficial insects, a wide range of susceptibility to insecticides has been reported $[37,46]$, which manifests itself in a different response in post-treatment behavior patterns. In this regard, it has been possible to verify that some species have practically negligible population values or are very absent in the agroecosystems subject to insecticidal applications (Conventional, IPM) while they are relatively common in ecological management $[31,35]$. This group includes predatory species such as snakefly, Harraphidia laufferi (Raphidioptera: Raphidiidae), ladybugs (Coleoptera: Coccinellidae) and pirate bugs such as Temnostethus sp. (Hemiptera: Anthocoridae). Its low population values in olive groves where insecticides are frequently applied could probably be due to their greater susceptibility to commercial doses of dimethoate, which would exceed the LD50 for them. Unlike species with behavioral resistance, these show a significantly lower capture rates in post-treatment chromatic traps, which allows them to be classified as BR-

The integration of chemical and biological control is an essential part of sustainable pest management; to maximize the compatibility between these two tactics [37], for which a correct interpretation of the impact of sublethal doses on beneficial insects is required [37,47-49]. The possibility of a more accurate interpretation of the monitoring data of the field experiments based on the application of small-scale inductor treatments opens up new possibilities of practical uses and applications. Among them, it can be used in the identification of organic olive groves, since it allows a clear differentiation from those that are object of insecticides applications (conventional, IPM). It is also very useful to define more clearly the period of conversion of a crop to obtain the certification of "organic farming." This process involves the replacement of highly polluting practices (such as the use of fertilizers, chemical pesticides, and deep soil tillage), for others that allow maintaining biodiversity, achieving the balance of fauna and flora, and ensuring the long-term productivity of the soil. During this period of agronomic conversion, agricultural exploitation is subject to frequent inspections by the institution in charge of granting certification, whose purpose is to verify the disappearance of pesticide residues and fertilizers, not allowed in organic production. This period is currently set at 3 years [50], although until now it has not been verified whether this period is sufficient to revert genetic lineages resistant to the behavior of beneficial insects to their wild form.

\section{Conclusion}

The studies whose results are here discussed have made it possible to classify the beneficial insects into capable / incapable of 
developing behavioral adaptations or behavioral resistance (BR + / BR-) against the commercial doses of the dimethoate insecticide. The presence / absence of behavioral resistance would ultimately allow them to have / lack insecticide escape mechanisms.

The beneficial insects capable of developing behavioral resistance, only manifest itself as $\mathrm{BR}+$ in agroecosystems that are frequently treated by insecticides. While populations of these species lack it (BR-) in organic agroecosystems.

The beneficial insects unable to develop behavioral resistance very probably do not survive the exposure of the commercial doses applied, so their presence is very often indicative of organic agroecosystems, so they are very scarce or even absent in insecticide-agroecosystems.

The implementation of small-scale insecticidal treatments in target crops, and the monitoring of the behavioral response of beneficial insects is proposed as a useful tool to identify true organic agroecosystems.

\section{Acknowledgement}

This research is part of the "Novel approaches to promote the sustainability of olive cultivation in the Mediterranean (SUSTAINOLIVE)" project, granted by the European Commission.

\section{Conflict of Interest}

No conflict of interest.

\section{References}

1. Knipling EF (1972) Entomology and the management of man's environment. Australian Journal of Entomology 11(3): 153-167.

2. Ehi-Eromosele CO, Nwinyi O, Ajani OO (2013) Integrated pest management. Pp. 1-12.

3. Karuppuchamy P, Venugopal S (2016) Integrated pest management. In Ecofriendly pest management for food security, pp. 651-684.

4. Haynes KF (1988) Sublethal effects of neurotoxic insecticides on insect behavior. Annual review of entomology 33(1): 149-168.

5. Fathipour Y, Sedaratian A (2013) Integrated management of Helicoverpa armigera in soybean cropping systems. Soybean-Pest Resistance. InTech, Rijeka, Croatia, pp. 231-280.

6. Orr A (2003) Integrated pest management for resource-poor African farmers: Is the emperor naked? World Development 31(5): 831-845.

7. Oliveira NCD, Wilcken CF, Matos CAO (2004) Ciclo biológico e predação de três espécies de coccinelídeos (Coleoptera, Coccinellidae) sobre o pulgão-gigante-do-pinus Cinara atlantica (Wilson) (Hemiptera, Aphididae). Revista Brasileira de Entomologia, pp. 529-533.

8. Parra JRP (2000) 0 controle biológico eo manejo de pragas: passado, presente e futuro. Bases Técnicas do Manejo de Insetos. UFSM. CCR. DFS. Santa Maria, Brazil, pp. 59-70.

9. Quinton JN, Edwards GM, Morgan RPC (1997) The influence of vegetation species and plant properties on runoff and soil erosion: results from a rainfall simulation study in south east Spain. Soil Use and Management 13(3): 143-148.

10. Kenmore PE, Heong KL, Putter CA (1985) Political, social and perceptual aspects of integrated pest management programmes. Malaysian Plant Protection Society 13(3): 143-148

11. Rodriguez E, Gonzalez B, Campos M (2012) Natural enemies associated with cereal cover crops in olive groves. Bulletin of Insectology 65(1): 4349.
12. Porcel M, Cotes B, Castro J, Campos M (2017) The effect of resident vegetation cover on abundance and diversity of green lacewings (Neuroptera: Chrysopidae) on olive trees. Journal of pest science 90(1): 195-206.

13. Laureto LMO, Cianciaruso MV, Samia DSM (2015) Functional diversity: an overview of its history and applicability. Natureza \& Conservação 13(2): 112-116.

14. Gómez JA, Campos M, Guzmán G, Castillo-Llanque F, Vanwalleghem T, et al. (2018) Soil erosion control, plant diversity, and arthropod communities under heterogeneous cover crops in an olive orchard. Environmental Science and Pollution Research 25(2): 977-989.

15. Dimitrova A, Livieratos I, Gkisakis V (2018) Trapping methodologies for functional canopy arthropod diversity in olive agroecosystem. $2^{\text {nd }}$ Mediterranean Forum Research and Innovation as Tools for Sustainable Agriculture, Food \& Nutrition Security, Italy.

16. Gkisakis VD, Bàrberi P, Kabourakis EM (2018) Olive canopy arthropods under organic, integrated, and conventional management. The effect of farming practices, climate and landscape. Agroecology and Sustainable Food Systems 42(8): 843-858.

17. González-Ruiz R, Gómez-Guzmán JA (2019) Agricultural Management Greatly Affects the Beneficial Entomofauna of the Olive Groves. Am J Biomed Sci \& Res 1(3).

18. Stark JD, Jepson PC, Mayer DF (1995) Limitations to use of topical toxicity data for predictions of pesticide side effects in the field. Journal of Economic Entomology 88(5): 1081-1088.

19. Desneux N, Decourtye A, Delpuech JM (2007) The sublethal effects of pesticides on beneficial arthropods. Annu Rev Entomol 52: 81-106.

20. de França SM, Breda MO, Barbosa DR, Araujo, AM, Guedes CA (2017) The sublethal effects of insecticides in insects. Biological control of pest and vector insects, 23.

21. Lee CY (2000) Sublethal effects of insecticides on longevity, fecundity and behaviour of insect pests: a review J Biosci 11(1): 107-112.

22. Singh JP, Marwaha KK (2000) Effect of sublethal concentrations of some insecticides on growth and development of maize stalk borer, Chilo partellus (Swinhoe) larvae. Shashpa 7(2): 181-186

23. He Y, Zhao J, Zheng Y, Weng Q, Biondi A, et al. (2013) Assessment of potential sublethal effects of various insecticides on key biological traits of the tobacco whitefly, Bemisia tabaci. International Journal of Biological Sciences 9(3): 246.

24. Legal L, David JR, Jallon JM (1992) Toxicity and attraction effects produced by Morinda citrifolia fruits on the Drosophila melanogaster complex of species. Chemoecology 3(3-4): 125-129.

25. Legal L, Chappe B, Jallon JM (1994) Molecular basis of Morinda citrifolia (L.): Toxicity on drosophila. Journal of Chemical Ecology 20(8): 19311943.

26. Choochote W, Tuetun B, Kanjanapothi D, Rattanachanpichai E, Chaithong U, et al. (2004). Potential of crude seed extract of celery, Apium graveolens L., against the mosquito Aedes aegypti (L.)(Diptera: Culicidae). J Vector Ecol 29(2): 340-346.

27. Morales J, Castillo J, Luna I (2010) Aceite esencial del fruto del noni (Morinda citrifolia: Rubiaceae) como larvicida del mosquito Aedes aegypti (Diptera: Culicidae). Tecnociencia 12(1): 53-64.

28. Levinson HZ (1975) Possibilities of using insectistatics and pheromones in pest control. Die Naturwissenschaften 62(6): 272-282.

29. Lund AE, Hollingworth RM, Shankland DL (1979) Chlordimeform: Plant protection by a sublethal, noncholinergic action on the central nervous system. Pesticide Biochemistry and Physiology 11(1-3): 117-128.

30. Linn CE, Roelofs W (1985) Multiple effects of octopamine and chlordimeform on pheromone response thresholds in the cabbage looper moth, Trichoplusia ni Pestic Sci 16: 445-46.

31. Lockwood JA, Byford RL, Story RN, Sparks TC, Quisenberry SS (1985) Behavioral resistance to the pyrethroids in the horn fly, Haematobia irritans (Diptera: Muscidae). Environmental Entomology 14(6): 873880. 
32. Anonymous (1991) Council Directive 91/414/EEC of 15 July 1991 concerning the placing of plant protection products on the market. Off J Eur Communities L230: 1-32.

33. Anonymous (1996) Commission Directive 96/12/EC of 8 March 1996 amending Council Directive 91/414/EEC concerning the placing of plant protection products on the market. Off J Eur Communities L65: 20-37.

34. Gómez-Guzmán JA, García-Marín FJ, Sáinz-Pérez M, González-Ruiz R (2017) Behavioural Resistance in Insects: Its Potential Use as Bio Indicator of Organic Agriculture. IOP Conference Series: Earth and Environmental Science 95(4): 1-10.

35. Gómez-Guzmán JA, González-Ruiz R (2020) The influence of agricultural olive growing practices on abundance and behavioral resistance of beneficial insects. Agronomy. Special Issue "Impact of Agricultural Practices on Biodiversity of Soil Invertebrates".

36. Varga M, Oltean I, Florian T (2018) Efficacy of Pheromone Traps/Yellow and Blue Sticky Panels and other Biological Methods to Fight against Western flower Thrips at Offer Madsen Gartneriet A/S Glamsbjerg, Denmark. ProEnvironment/ProMediu 11(35).

37. Ail-Catzim CE, Cerna-Chávez E, Landeros-Flores J, Ochoa-Fuentes Y, García-López AM, et al. (2015) Efecto de Insecticidas Sobre la Mortalidad y Depredación de Chrysoperla carnea (Neuroptera: Chrysopidae). Southwestern Entomologist 40(3): 565-575.

38. González-Ruiz R, Gómez-Guzmán JA (2019) Agricultural Management Greatly Affects the Beneficial Entomofauna of the Olive Groves. Am J Biomed Sci \& Res 1(3)

39. Bozsik A, González-Ruíz R, Hurtado-Lara B (2009) Distribution of the Chysoperla carnea complex in southern Spain (Neuroptera: Chrysopidae). Analele Universității din Oradea, Fascicula: Protecția Mediului 14: 60-65.

40. Kennedy JS (1947) The excitant and repellent effects on mosquitos of sub-lethal contacts with DDT. Bulletin of entomological research 37(4): 593-607.
41. Rolff J, Reynolds S (2009) Insect infection and immunity: evolution, ecology, and mechanisms (No. 25). Oxford university press.

42. Pike KS, Mayer DF, Glazer M, Kious C (1982) Effects of permethrin on mortality and foraging behavior of honeybees in sweet corn. Environmental Entomology 11(4): 951-953.

43. Haynes KF, Li WG, Baker TC (1986) Control of pink bollworm moth (Lepidoptera: Gelechiidae) with insecticides and pheromones (attracticide): lethal and sublethal effects. Journal of Economic Entomology 79(6): 1466-1471.

44. Moore RF (1980) Behavioral and biological effects of NRDC-161 as factors in control of the boll weevil. Journal of Economic Entomology 73(2): 265-267.

45. Pree DJ, Archibald DE, Morrison RK (1989) Resistance to insecticides in the common green lacewing Chrysoperla carnea (Neuroptera: Chrysopidae) in southern Ontario. Journal of economic Entomology 82(1): 29-34.

46. Nasreen A, Mustafa G, Ashfaq M (2005) Mortality of Chrysoperla carnea (Stephens) (Neuroptera: Chrysopidae) after exposure to some insecticides; laboratory studies. South Pacific Studies 26(1): 1-6.

47. Georghiou GP (1972) The evolution of resistance to pesticides. Annual Review of Ecology and Systematics 3(1): 133-168.

48. Lockwood JA, Sparks TC, Story RN (1984) Evolution of insect resistance to insecticides: a reevaluation of the roles of physiology and behavior. Bulletin of the Esa 30(4): 41-51.

49. Guedes NMP, Guedes RNC, Ferreira GH, Silva LB (2009) Flight take-off and walking behavior of insecticide-susceptible and-resistant strains of Sitophilus zeamais exposed to deltamethrin. Bulletin of entomological research 99(4): 393-400.

50. González A, Redondo F, Arrebola F, Casado J, Camps M, Rull P, Sánchez R (2011) Manual de conversión a la producción ecológica. Instituto de Investigación y Formación Agraria y Pesquera: Consejería de Agricultura y Pesca Sevilla Pp. 184. 